\title{
Effect of oxidized low-density lipoprotein on the expression of the prorenin receptor in human aortic smooth muscle cells
}

\author{
YUNPENG CHENG ${ }^{*}$, XIAOYUN LIU*, LIJIAO ZHANG, YING ZHANG, YING LIU, YAN LU and YINONG JIANG \\ Department of Cardiology, The First Affiliated Hospital of Dalian Medical University, Dalian, Liaoning 116011, P.R. China
}

Received February 13, 2014; Accepted December 17, 2014

DOI: $10.3892 / \mathrm{mmr} .2015 .3254$

\begin{abstract}
The activation of the (pro)renin receptor (PRR) may be potentially active in the development of atherosclerotic plaques independent of angiotensin II. Our previous studies demonstrated that high glucose was able to induce the activation of PRR. The present study was designed to determine the function of oxidized low-density lipoprotein (ox-LDL) on the expression of PRR in human aortic smooth muscle cells (HASMCs). Immunofluorescence revealed that PRR was expressed in HASMCs. HASMCs were cultured with $100 \mu \mathrm{g} / \mathrm{ml}$ ox-LDL for 1, 2, 4, 6, 12 and $24 \mathrm{~h}$, respectively. Subsequently, HASMCs were cultured with 25, 50, 100, 150, 200 and $300 \mu \mathrm{g} / \mathrm{ml}$ ox-LDL for $6 \mathrm{~h}$, respectively. Reverse transcription-quantitative polymerase chain reaction and western blot analysis revealed that the expression of PRR was markedly upregulated in a time- and concentration-dependent manner, which peaked at $6 \mathrm{~h}$ and $50 \mu \mathrm{g} / \mathrm{ml}$, then slowly decreased. Therefore, PRR may contribute to the atherogenesis effect induced by ox-LDL.
\end{abstract}

\section{Introduction}

Atherosclerosis and cardiovascular disease remain one of the major causes of mortality worldwide. Ox-LDL has a central proatherogenic role in the arterial wall (1-3). It has a multitude of actions on vascular smooth muscle cells, including inducing their migration and proliferation as well as altering their phenotype to foam cells (4-6). Ox-LDL also results in the generation of reactive oxygen species (ROS) from vascular smooth muscle cells (7). Ox-LDL, through increasing ROS production, leads to an increase in the generation of a variety

Correspondence to: Professor Yinong Jiang, Department of Cardiology, The First Affiliated Hospital of Dalian Medical University, 222 Zhongshan Road, Dalian, Liaoning 116011, P.R. China

E-mail: yinongjiang@126.com

*Contributed equally

Key words: prorenin receptor, human aortic smooth muscle cells, oxidized low-density lipoprotein, atherosclerosis of growth factors, including fibroblast growth factor $(8,9)$, insulin-like growth factor-1 (10) and epidermal growth factor (11) as well as expression of their receptors, therefore inducing vascular smooth muscle cell proliferation and hypertrophy. Ox-LDL is also able to induce apoptosis in smooth muscle cells (12).

The (pro)renin receptor (PRR) constitutes a novel component of the renin-angiotensin system (RAS) and has attracted significant attention in previous years due to its versatile functions (13). Numerous studies have verified that when the renin precursor binds to its receptor, it directly triggers angiotensin II independent reactions, which may be potentially active in the development of atherosclerotic plaques $(14,15)$. The binding to PRR and the ability to induce a signal transduction cascade independent of the generation of angiotensin II $(13,16)$, including the activation of mitogen-activated protein kinase (MAPK) (17) and enhancement of the phosphorylation of extracellular signal-regulated kinase (ERK1/2) (18), promotes fibrosis gene expression, including transforming growth factor- $\beta$, plasminogen activator inhibitor-1, fibronectin and collagen proteins $(19,20)$. However, to the best of our knowledge, there is little data demonstrating the direct effect of the atherogenic condition on the PRR.

A previous study by our group demonstrated that the conditions of atherogenesis, including high glucose and high blood lipids were able to upregulate the expression of PRR in cultured human umbilical vein endothelial cells (21). Therefore, cultured human aortic smooth muscle cells (HASMCs) were utilized to investigate the effect of ox-LDL on the expression of PRR.

\section{Materials and methods}

Cell culture. HASMCs were obtained from Lifeline Cell Technology (Beijing, China) and cultured according to the manufacturer's instructions. The cells were cultured in Vasculife SMC cell culture medium, containing VascuLife basal medium and LifeFactors SMC (cat no. LS-1040; Lifeline Cell Technology) at $37^{\circ} \mathrm{C}$ in an atmosphere of $95 \%$ air and $5 \% \mathrm{CO}_{2}$ according to the manufacturer's instructions. Cells were seeded in six-well plates and the culture medium was changed daily. Prior to each experimental treatment, cells were serum starved for $24 \mathrm{~h}$ under serum-free conditions. The concentration of human ox-LDL (24.5 nmoles of MDA/mg protein; Qingdao Haicon Biotechnology Co., Ltd., Qingdao, 
China) was primarily based on a previously published study demonstrating their effectiveness in vascular smooth muscle cells (21). According to these results, $100 \mu \mathrm{g} / \mathrm{ml}$ ox-LDL was used to stimulate HASMCs for different time periods, which were divided into 1, 2, 4, 6, 12 and 24 h subgroups. Subsequently, the strongest expression time point of PRR was selected and cells were treated with different concentrations of ox-LDL, which were divided into 25, 50, 100, 150, 200 and $300 \mu \mathrm{g} / \mathrm{ml}$ subgroups. At the end of each experiment, cells were harvested for the preparation of whole-cell lysates and total RNA extraction.

Immunofluorescence. The expression of PRR in HASMCs was detected using immunofluorescence staining. HASMCs were seeded at a density of $5 \times 10^{4}$ cells $/ \mathrm{ml}$ into 24 -well plates, cultivated and divided into groups. At the end of culture, the HASMCs were fixed with paraformaldehyde for $30 \mathrm{~min}$. Cells were incubated with the primary antibody (polyclonal rabbit anti-human ATP6IP2 antibody; 1:700 dilution; ab64975; Abcam, Cambridge, MA, USA) at $4^{\circ} \mathrm{C}$ overnight. Following incubation with the fluorescein-labeled secondary antibody (fluorescein isothiocyanate-conjugated goat anti-rabbit immunoglobulin G; 1:200; sc-2012, Santa Cruz Biotechnology, Inc., Dallas, TX, USA) at $37^{\circ} \mathrm{C}$ for $40 \mathrm{~min}$, HASMCs were observed using fluorescence microscopy (DM4000 B LED; Leica, Mannheim, Germany) and images were immediately captured. The same process without the primary antibody and secondary antibody was used as a negative control. Green fluorescence of the cell membrane indicated positive expression of PRR.

Reverse transcription-quantitative polymerase chain reaction $(R T-q P C R)$. Total RNA was extracted immediately from cultured cells using TRIzol reagent (Gibco-BRL, Dalian, China) according to the manufacturer's instructions. Total RNA was reverse transcribed using the Prime Script RT reagent kit with gDNA Eraser (Perfect Real Time; Takara Bio Inc., Dalian, China). RT-qPCR was performed using SYBR Premix Ex Taq ${ }^{\mathrm{TM}}$ II (Takara Bio Inc.) with the Roche LightCycler $^{\circledR} 480$ Sequence Detection System (Roche Diagnostics GmbH, Mannheim, Germany). Samples were run in triplicate in separate tubes to permit quantification of the target gene normalized to GAPDH, which was used for equal loading. Primer sequences are shown in Table I. The PCR amplification program was as follows: $95^{\circ} \mathrm{C}$ for $30 \mathrm{sec}, 95^{\circ} \mathrm{C}$ for $5 \mathrm{sec}$ and $60^{\circ} \mathrm{C}$ for $20 \mathrm{sec}$ for 40 cycles.

Western blot analysis. Cells were lysed in $100 \mu \mathrm{l}$ of lysis buffer (Nanjing KeyGen Biotech. Co., Ltd., Nanjing, China). Protein concentrations were measured using a protein assay kit (Nanjing KeyGen Biotech. Co., Ltd.). The protein $(25 \mu \mathrm{g})$ obtained from each lysate was electrophoresed on a $15 \%$ SDS-polyacrylamide gel $(90 \mathrm{mV}, 30 \mathrm{~min} ; 130 \mathrm{mV}, 90 \mathrm{~min})$ and transferred onto a nitrocellulose membrane (Merck Millipore, Darmstadt, Germany) using a Mini-PROTEAN 3 system (120 mV, 1.5 h; Bio-Rad, Hercules, CA, USA). The membrane was incubated overnight with polyclonal rabbit anti-human ATP6AP2 antibody (1:700 dilution; Abcam) and polyclonal rabbit anti-human $\beta$-actin (1:500 dilution; bs-0061R; Bioss, Beijing, China). The specific binding
Table I. Primers used for reverse transcription-quantitative polymerase chain reaction.

Gene $\quad$ Sequence (5'-3')

\section{ATP6AP2 \\ (NM_005765) \\ Forward \\ Reverse \\ TGGAAATTGGCCTATACCAGGAG \\ GAPDH GTAGCCCGAGGACGATGAAAC \\ (NM_002046) \\ Forward \\ GCACCGTCAAGGCTGAGAAC \\ Reverse}

was detected using horseradish peroxidase-labeled goat anti-rabbit IgG (1:7,500; ZSGB-BIO, Beijing, China) and an enhanced chemiluminescence detection kit (Perkin-Elmer, Waltham, MA, USA). The bands were quantified using Image Pro-Plus 5.0 software (Media Cybernetics, Rockville, MD, USA).

Statistical analysis. Standard statistical methods from the SPSS statistical analysis system 16.0 (SPSS, Inc., Chicago, IL, USA) were used. Statistical comparisons were made using a two-way analysis of variance. Data are presented as the mean \pm standard error of the mean. $\mathrm{P}<0.05$ was considered to indicate a statistically significant difference. Duplicate wells were analyzed for each experiment and each experiment was performed independently at least three times.

\section{Results}

PRR expression in HASMCs. Immunofluorescence techniques verified that PRR was expressed in HASMCs (Fig. 1), indicating that PRR was abundant in HASMCs and mainly present in the cell membrane and cytoplasm.

Effect of ox-LDL on the expression of PRR at different time periods. HASMCs were incubated with a final concentration of $100 \mu \mathrm{g} / \mathrm{ml}$ ox-LDL for $0,1,2,4,6,12$ and $24 \mathrm{~h}$. It was found that the expression of PRR was significantly upregulated by ox-LDL in a time-dependent manner (Fig. 2). The mRNA and protein expression of PRR began to increase $2 \mathrm{~h}$ following incubation and reached a peak level at $6 \mathrm{~h}$ and then decreased moderately, however, maintaining a higher level of expression than the control group at $24 \mathrm{~h}$.

Effect of ox-LDL on the expression of PRR at different concentrations. Based on the above results, HASMCs were incubated with $0,25,50,100,150,200$ and $300 \mu \mathrm{g} / \mathrm{ml}$ ox-LDL for $6 \mathrm{~h}$, respectively. Compared with the control group, the expression of PRR mRNA increased in the group treated with $25 \mu \mathrm{g} / \mathrm{ml}$, reached a peak in the $50 \mu \mathrm{g} / \mathrm{ml}$ group, then decreased moderately in the remaining groups (Fig. 3A), revealing a concentration-dependent effect. The expression of PRR protein was similar to that of the mRNA, however, maintained significantly higher levels than the control group following decrease (Fig. 3B). 

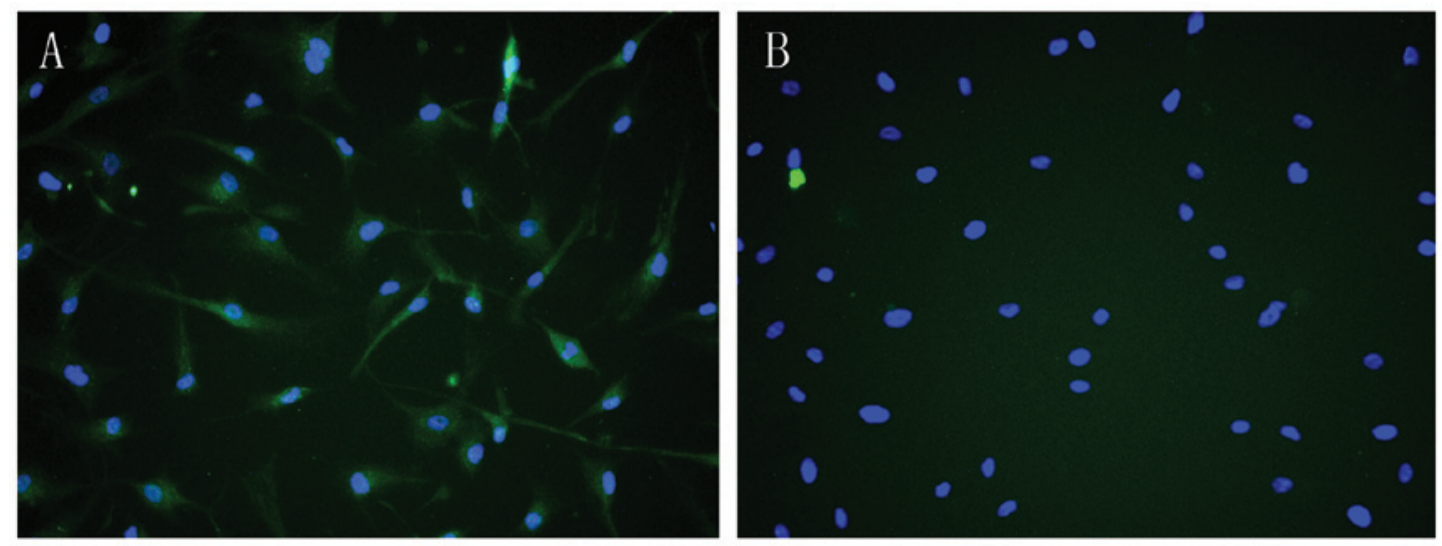

Figure 1. Expression of the (pro)renin receptor in human aortic smooth muscle cells. Nuclear staining with Hoechst. (A) Staining for (pro)renin receptor (green fluorescence). (B) Negative control (magnification, x200).

A

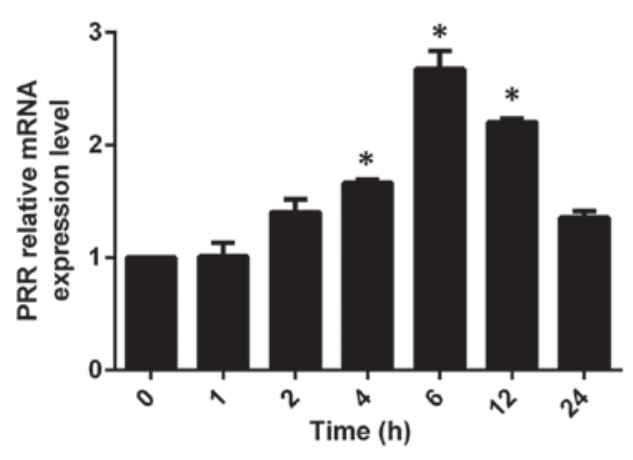

B
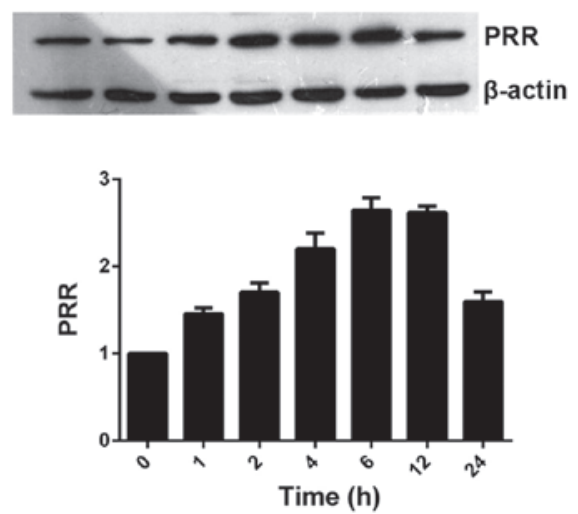

Figure 2. (A) Expression of the PRR in human aortic smooth muscle cells stimulated by $100 \mu \mathrm{g} / \mathrm{ml}$ ox-LDL for different time periods detected by reverse transcription-quantitative polymerase chain reaction and (B) western blot analysis." $<<0.05$ vs. the control group. PRR, (pro)renin receptor.

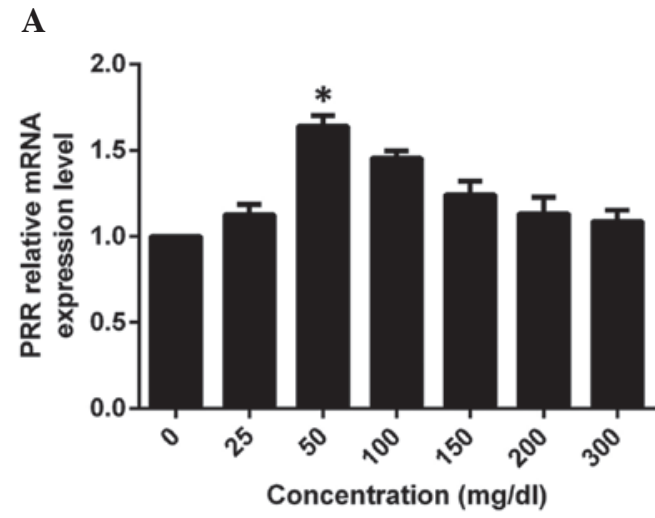

B
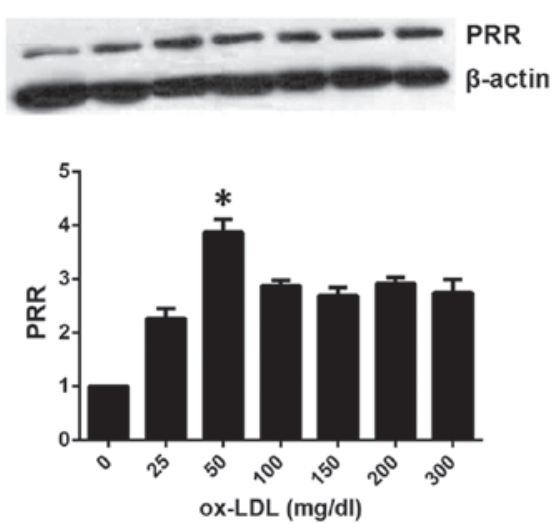

Figure 3. (A) Expression of the PRR in human aortic smooth muscle cells stimulated by different concentrations of ox-LDL for 6 h detected by reverse transcription-quantitative polymerase chain reaction and (B) western blot analysis. ${ }^{\mathrm{P}}<0.05$ vs. the control group. PRR, (pro)renin receptor.

\section{Discussion}

In the present study, immunofluorescence demonstrated that PRR was expressed on the cell membrane and cytoplasm in HASMCs (Fig. 1A), which is consistent with a previous study (22) and the PRR was abundant in HASMCs.

Binding of (pro)renin to the PRR increases the catalytic activity of prorenin and renin, resulting in increased RAS activation (13). Additionally, intracellular signaling cascades, including the MAPK and ERK1/2 pathways as well as the phosphorylation of heat shock protein 27 (HSP 27) $(18,23,24)$ are triggered, resulting in the expression of profibrotic and inflammatory molecules. These effects promote the occurrence and development of atherosclerosis.

The present study demonstrated that the expression of PRR was upregulated in a time- and concentration-dependent 
manner stimulated by ox-LDL, indicating that PRR is involved in ox-LDL-induced atherosclerosis. This demonstrated the effect of ox-LDL on the expression of PRR for the first time, to the best of our knowledge.

However, the mechanisms underlying atherosclerosis formation induced by ox-LDL are varied, including via its own LOX-1 receptor, promoting the generation of ROS, promoting the formation of foam cells and promoting the phenotypic transformation of SMC.

Therefore, whether the upregulation of PRR expression was induced by ox-LDL directly remains to be elucidated. Further studies are required to determine the association between PRR and LOX-1, the receptor of ox-LDL.

\section{References}

1. Ananyeva NM, Tjurmin AV, Berliner JA, et al: Oxidized LDL mediates the release of fibroblast growth factor-1. Arterioscler Thromb Vasc Biol 17: 445-453, 1997.

2. Li D, Liu L, Chen H, Sawamura T, Ranganathan S and Mehta JL: LOX-1 mediates oxidized low-density lipoprotein-induced expression of matrix metalloproteinases in human coronary artery endothelial cells. Circulation 107: 612-617, 2003.

3. Cai $\mathrm{H}$ and Harrison DG: Endothelial dysfunction in cardiovascular diseases: The role of oxidant stress. Circ Res 87: 840-844, 2000

4. Chisolm GM 3rd and Chai Y: Regulation of cell growth by oxidized LDL. Free Radic Biol Med 28: 1697-1707, 2000.

5. Chai YC, Binion DG, Macklis R and Chisolm GM 3rd: Smooth muscle cell proliferation induced by oxidized LDL-borne lysophosphatidylcholine. Evidence for FGF-2 release from cells not extracellular matrix. Vascul Pharmacol 38: 229-237, 2002.

6. Shen CM, Mao SJ, Huang GS, Yang PC and Chu RM: Stimulation of smooth muscle cell proliferation by ox-LDL- and acetyl LDL-induced macrophage-derived foam cells. Life Sci 70 443-452, 2001.

7. Hsieh CC, Yen MH, Yen CH and Lau YT: Oxidized low density lipoprotein induces apoptosis via generation of reactive oxygen species in vascular smooth muscle cells. Cardiovasc Res 49: 135-145, 2001.

8. Chang PY, Luo S, Jiang T, et al: Oxidized low-density lipoprotein downregulates endothelial basic fibroblast growth factor through a pertussis toxin-sensitive G-protein pathway: Mediator role of platelet-activating factor-like phospholipids. Circulation 104 588-593, 2001.

9. Chen CH, Jiang W, Via DP, et al: Oxidized low-density lipoproteins inhibit endothelial cell proliferation by suppressing basic fibroblast growth factor expression. Circulation 101: 171-177, 2000
10. Higashi Y, Peng T, Du J, et al: A redox-sensitive pathway mediates oxidized LDL-induced downregulation of insulin-like growth factor-1 receptor. J Lipid Res 46: 1266-1277, 2005.

11. Gao P, Wang XM, Qian DH, et al: Induction of oxidative stress by oxidized LDL via meprin $\alpha$-activated epidermal growth factor receptor in macrophages. Cardiovasc Res 97: 533-543, 2013.

12. Nishio E, Arimura S and Watanabe Y: Oxidized LDL induces apoptosis in cultured smooth muscle cells: a possible role for 7-ketocholesterol. Biochem Biophys Res Commun 223: 413-418, 1996.

13. Nguyen G, Delarue F, Burcklé C, Bouzhir L, Giller T and Sraer JD: Pivotal role of the renin/prorenin receptor in angiotensin II production and cellular responses to renin. J Clin Invest 109: 1417-1427, 2002.

14. Nguyen G: Renin/prorenin receptors. Kidney Int 69: 1503-1506, 2006.

15. Oliver JA: Receptor-mediated actions of renin and prorenin. Kidney Int 69: 13-15, 2006.

16. Funke-Kaiser H, Zollmann FS, Schefe JH and Unger T: Signal transduction of the (pro)renin receptor as a novel therapeutic target for preventing end-organ damage. Hypertens Res 33: 98-104, 2010.

17. Sakoda M, Ichihara A, Kaneshiro Y, et al: (Pro)renin receptor-mediated activation of mitogen-activated protein kinases in human vascular smooth muscle cells. Hypertens Res 30: 1139-1146, 2007.

18. Feldt S, Batenburg WW, Mazak I, et al: Prorenin and renin-induced extracellular signal-regulated kinase $1 / 2$ activation in monocytes is not blocked by aliskiren or the handle-region peptide. Hypertension 51: 682-688, 2008.

19. Huang Y, Wongamorntham S, Kasting J, et al: Renin increases mesangial cell transforming growth factor-beta1 and matrix proteins through receptor-mediated, angiotensin II-independent mechanisms. Kidney Int 69: 105-113, 2006.

20. Huang Y, Noble NA, Zhang J, Xu C and Border WA: Renin-stimulated TGF-beta1 expression is regulated by a mitogen-activated protein kinase in mesangial cells. Kidney Int 72: 45-52, 2007.

21. Hu X: Oxidized low density lipoprotein activates ERK 1/2 pathway via (pro)renin receptor in human umbilical vein endothelial cells. Chinese Journal of Integrative Medicine on Cardio/ Cerebrovascular Disease 10: 1235-1237, 2013 (In Chinese).

22. Greco CM, Camera M, Facchinetti L, et al: Chemotactic effect of prorenin on human aortic smooth muscle cells: a novel function of the (pro)renin receptor. Cardiovasc Res 95: 366-374, 2012.

23. Kaneshiro Y, Ichihara A, Sakoda M, et al: Slowly progressive, angiotensin II-independent glomerulosclerosis in human (pro)renin receptor-transgenic rats. J Am Soc Nephrol 18: 1789-1795, 2007.

24. Abassi Z, Winaver J and Feuerstein GZ: The biochemical pharmacology of renin inhibitors: implications for translational medicine in hypertension, diabetic nephropathy and heart failure: expectations and reality. Biochem Pharmacol 78: 933-940, 2009. 